\title{
Use of Clonally Replicated Seedlings in Field Screening for Resistance to Peach Tree Short Life
}

\author{
T.G. Beckman ${ }^{1}$, W.R. Okie ${ }^{1}$, and A.P. Nyczepir ${ }^{1}$ \\ Southeastern Fruit and Tree Nut Research Laboratory, Agricultural Research Service, U.S. \\ Department of Agriculture, P.O. Box 87, Byron, GA 31008
}

Additional index words. Criconemella xenoplax, Prunus persica, rootstock breeding

\begin{abstract}
Clonally replicated peach seedlings [Prunus persica (L.) Batsch] of Lovell, Nemaguard, and four $F_{1}$ selections of Lovell $\times$ Nemared were tested for field survival on a peach tree short life site. Rootstock families differed in growth, survival, and longevity. Genetic variation was similar to environmental variation for most families. Based on seedling within rootstock family, estimated broad-sense heritabilities for survival and longevity were high. The use of clonally replicated seedlings allowed the selection of apparently superior individuals from both Lovell and the other more short-lived rootstock families in a single screening.
\end{abstract}

The ring nematode [Criconemella xenoplax (Raski) Luc \& Raski] $(\mathrm{Cx})$ is a primary predisposing factor in the peach tree short life (PTSL) syndrome (Nyczepir, 1990; Nyczepir et al., 1983; Ritchie and Clayton, 1981). Lovell is the recommended rootstock for use on PTSL sites in the southeastern United States (Brittain and Miller, 1978) where it provides at least a marginal improvement in tree survival. On sites with root-knot nematode (Meloidogyne spp.) problems, Nemaguard or Nemared are recommended, but they are shorter lived than Lovell where PTSL is present.

Pre- and postplant chemical control of ring and root-knot nematodes is recommended. However, the long-term commitment and cost required for effective chemical control makes the development of rootstocks resistant to both PTSL and root-knot nematodes an attractive alternative. Since 1981, the U.S. Department of Agriculture-Agricultural Research Service (USDAARS) at Byron, Ga., has been evaluating peach and plum (Prunus spp.) germplasm for field tolerance/resistance to PTSL. The purpose of this research has been to identify superior lines either for direct use as seedling or clonal rootstocks or for use in the development of new rootstocks. Such screening generally uses unbudded seedlings of test families in field tests of 5 to 8 years duration.

Peach rootstocks are generally grown from seed; therefore, variability in plant performance (seedling to seedling) within a rootstock family may be due to genetic and/or environmental causes. The purpose of this experiment was to use clonally replicated seedlings to study sources of variation affecting tree survival on PTSL sites.

\section{Materials and Methods}

Open-pollinated seedlings of Lovell, Nemaguard, K62-67, K62-68, P101-40, and P101-41 were tested. The latter four are $\mathrm{F}_{1}$ selections of Lovell $\mathrm{x}$ Nemared made by D.R. Ramming (USDA, Fresno, Calif.), who supplied the seed. Although the tested rootstocks were not a truly random set, they typify the rootstocks used in the southeastern United States on PTSL sites and the material likely to be used as parents in our rootstock

Received for publication 21 Oct. 1991. Accepted for publication 26 May 1992. We thank Bruce Topp, Granite Belt Horticultural Research Station, Queensland, Australia, for his suggestions and comments during the preparation of this manuscript. The cost of publishing this paper was defrayed in part by the payment of page charges. Under postal regulations, this paper therefore must be hereby marked advertisement solely to indicate this fact.

${ }^{1}$ Research Horticulturist.

${ }^{2}$ Research Nematologist. development program. Seed of each line were stratified and planted in the greenhouse in Fall 1983. When plants were $\approx 30$ $\mathrm{cm}$ tall, 12 seedlings were randomly selected (except for leaf color) from each line and propagated vegetatively (Okie, 1984) to provide eight replicates (ramets) of each seedling. Only homozygous red-leaf seedlings were used for the numbered selections, so that any superior genotypes selected would already carry this desirable nursery characteristic.

Trees were transplanted to the field in Dec. 1984 at the Southeastern Fruit and Tree Nut Research Laboratory in central Georgia on a site with a history of PTSL. The spatial pattern of tree death observed in the previous planting was used as the basis for blocking in this experiment. Trees were planted $1.2 \mathrm{~m}$ apart within the row and in paired rows $1.9 \mathrm{~m}$ apart. Row pairs were $6.2 \mathrm{~m}$ apart (center to center). Each of the eight randomized complete blocks contained a ramet of each of 12 seedlings from each of six rootstock treatments (families) resulting in 72 single tree plots randomized within each block. Soil type was a Faceville fine sandy loam, a clayey, kaolinitic, thermic, Typic $\mathrm{Pa}$ leudult.

A herbicide strip was maintained within the double rows with a grass sod between double rows. Trees were fertilized each spring with a single broadcast application of ammonium nitrate $\left(56 \mathrm{~kg} \cdot \mathrm{ha}^{-1} \mathrm{~N}\right)$. No supplemental irrigation was applied. Trees were initially trained by hand to an open center. However, commencing in Fall 1987, trees were pruned with a tractormounted sickle bar mower that removed about one-third of the previous season's growth from the top and outside (facing tractor row) of each tree. Suckers were removed annually.

Trunk diameters were measured $30 \mathrm{~cm}$ from the soil line shortly after planting and at the end of each growing season for the first 3 years. Trunk cross-sectional area was calculated. Dead and dying trees were inspected each spring (typically early May) through 1991 to determine the cause of death, i.e., PTSL, oak root rot [Armillaria tabescens (Scop.) Dennis, Orton and Hora], or unknown. Trees that died from causes other than PTSL were excluded from subsequent analyses (resulting in the loss of 40 trees over the course of the experiment). Soil samples (four cores/tree, each $2.5 \mathrm{~cm}$ diameter $\times 30 \mathrm{~cm}$ deep; cores combined before analysis) were collected each fall from all surviving ramets of one Lovell seedling and one Nemaguard seedling (same seedling each year). Nematodes were extracted from a $100 \mathrm{~cm}^{3}$ subsample by elutriation (Byrd et al., 1976) and centrifugation (Jenkins, 1964) and then counted.

Abbreviation: PTSL, peach tree short life. 
Growth, survival, and longevity data were analyzed with the general linear models (GLM) procedure of SAS (SAS Institute, 1987) using a nested, cross-classified design, although we recognize the limitations of this analysis on binomial survival data $(0=$ dead, $1=$ alive $)$. Block and rootstock were considered fixed effects for analysis. Variance components were estimated using PROC VARCOMP (SAS Institute, 1987) and a random effects model to allow calculation of all components. Broadsense heritability was calculated based on clonal means (Dudley and Moll, 1969). Theoretical variances of rootstock family means were calculated for varying numbers of blocks (ramets) and seedlings (Jones et al., 1960). Survival and longevity data were also analyzed for each rootstock family by GLM. Genetic (seedling) and environmental (block) variances were compared for each family using a folded F test (SAS Institute, 1987). Nematode population data were transformed as square root of count and analyzed as a split-plot in time using GLM.

\section{Results and Discussion}

Averaged over years, mean population density of $\mathrm{Cx}$ was lower $(P<0.0001)$ around Lovell than Nemaguard (Fig. 1). Counts from individual samples varied widely but most were in the range normally associated with severe PTSL sites (Sharpe et al., 1989). Since soil samples from each line were obtained from ramets of a single seedling, all variation was considered attributable to environment rather than host genotype. The wide variation in counts indicates samples from individual trees are not reliable indicators of genetic differences in host suitability but represent variations relating to site factors. Decline in counts over time $(P<0.05)$ may have resulted from lack of tree vigor due to overcrowding or from other unknown biological factors.

Although trunk cross-sectional area of rootstock families differed markedly $(P<0.0001)$ during the test (Table 1 , selected years shown), correlations between trunk cross-sectional area or relative growth rate and longevity were low (data not shown), indicating that neither the largest nor smallest trees were more likely to die.

Rootstock families differed in their survival (percent alive, $P$ $<0.08$ ) and longevity (mean tree life, $P<0.01$ ) (Table 1 ). Lovell seedlings displayed greater longevity than all other fam-

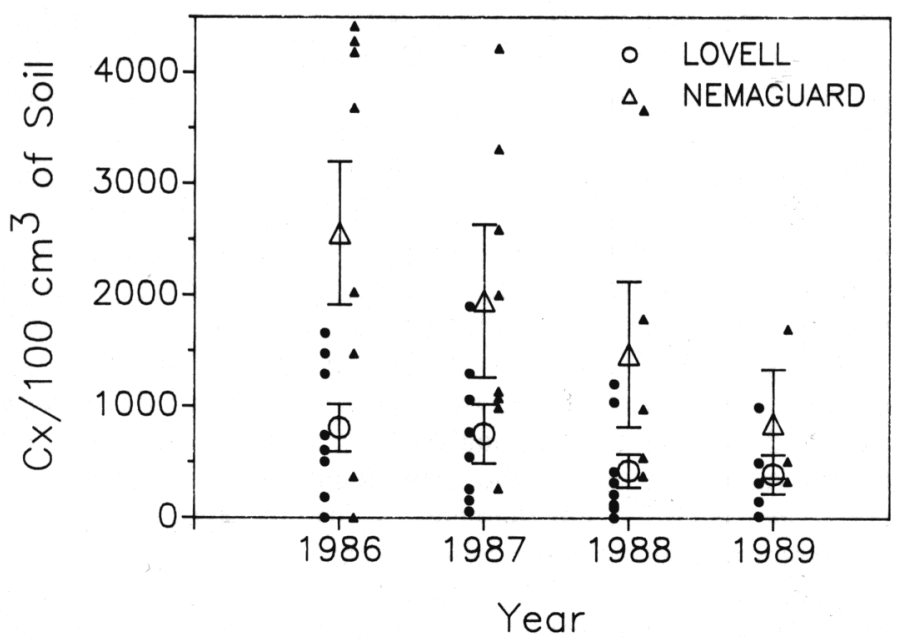

Fig. 1. Population density of Criconemella xenoplax beneath ramets of an individual seedling of Lovell and Nemaguard. Large, open symbols represent mean- $( \pm$ SE). Small, closed- symbols represent individual samples (= ramet). Figure based on raw untransformed data.
Table 1. Rootstock effect on tree growth, survival, and longevity during PTSL field screen using clonally replicated seedlings.

\begin{tabular}{|c|c|c|c|c|}
\hline \multirow[b]{2}{*}{ Family $^{z}$} & \multicolumn{2}{|c|}{$\begin{array}{c}\text { Trunk } \\
\text { cross-sectional } \\
\text { area }\left(\mathrm{cm}^{2}\right)\end{array}$} & \multirow{2}{*}{$\begin{array}{l}\text { Survivaly } \\
\text { (\% alive) }\end{array}$} & \multirow{2}{*}{$\begin{array}{c}\text { Longevity' } \\
\text { (years) }\end{array}$} \\
\hline & 1985 & 1988 & & \\
\hline Lovell & $0.40 b^{x}$ & $16.22 \mathrm{~b}$ & $50.0 \mathrm{a}$ & $6.0 \mathrm{a}$ \\
\hline Nemaguard & $0.50 \mathrm{a}$ & $23.93 \mathrm{a}$ & $28.6 \mathrm{ab}$ & $4.9 \mathrm{~b}$ \\
\hline P101-41 & $0.21 \mathrm{c}$ & $12.85 \mathrm{c}$ & $25.6 \mathrm{ab}$ & $4.9 \mathrm{~b}$ \\
\hline K62-68 & $0.09 \mathrm{e}$ & $14.59 \mathrm{bc}$ & $24.7 \mathrm{ab}$ & $4.9 \mathrm{~b}$ \\
\hline P101-40 & $0.17 \mathrm{dc}$ & $15.58 \mathrm{bc}$ & $21.1 \mathrm{~b}$ & $4.8 \mathrm{~b}$ \\
\hline K62-67 & $0.11 \mathrm{de}$ & $14.86 \mathrm{bc}$ & $15.9 \mathrm{~b}$ & $4.6 \mathrm{~b}$ \\
\hline MSD & 0.07 & 2.86 & 27.7 & 0.8 \\
\hline
\end{tabular}

${ }^{\mathrm{z}}$ Numbered selections are $\mathrm{F}_{1}$ selections of Lovell $\mathrm{x}$ Nemared.

${ }^{\mathrm{y}}$ Through Spring 1991; maximum possible life $=7$ years.

${ }^{\mathrm{x}}$ Mean separation in columns via Waller-Duncan K-Ratio Test (K Ratio $=100) ; \mathrm{MSD}=$ minimum significant difference.

Table 2. Environmental (block) and genetic (seedling) mean squares of survival and longevity within rootstock families.

\begin{tabular}{|c|c|c|c|c|c|}
\hline \multirow[b]{2}{*}{ Family } & \multirow{2}{*}{$\begin{array}{c}\text { Error } \\
\text { df }\end{array}$} & \multicolumn{2}{|c|}{$\begin{array}{l}\text { Survival } \\
\text { (\% alive) }\end{array}$} & \multicolumn{2}{|c|}{$\begin{array}{c}\text { Longevity } \\
\text { (years) }\end{array}$} \\
\hline & & Block & Seedling & Block & Seedling \\
\hline Lovell & 69 & $0.70 * * *$ & $0.57 * * *$ & $2.00^{\mathrm{NS}}$ & $3.99 * * *$ \\
\hline Nemaguard & 72 & $0.15^{\mathrm{NS}}$ & $1.09 * * *$ & $4.47 * * *$ & $11.53 * * *$ \\
\hline P101-41 & 67 & $0.13^{\mathrm{NS}}$ & $0.84 * * *$ & $5.06 * * *$ & $7.52 * * *$ \\
\hline K62-68 & 74 & $0.46^{* *}$ & $0.32^{*}$ & $9.84 * * *$ & $3.73^{* *}$ \\
\hline P101-40 & 71 & $0.56 * * *$ & $0.34 * *$ & $5.97 * * *$ & $5.19 * * *$ \\
\hline K62-67 & 69 & $0.11^{\mathrm{NS}}$ & $0.19^{\mathrm{NS}}$ & $6.21 * * *$ & $3.41^{* *}$ \\
\hline
\end{tabular}

$\mathrm{NS},{ }^{*}, * * * * * \mathrm{~F}$ test nonsignificant or significant at $\mathrm{P}=0.05,0.01$, or 0.001 levels, respectively, using block $\times$ seedling as error term.

ilies included in this test. The superior longevity of Lovell compared with that of Nemaguard substantiates previous observations of grafted tree performance on PTSL sites in the southeastern United States (Dozier et al., 1984; Sharp et al., 1989).

In analysis of survival and longevity by rootstock family, the $F$ test for seedling differences was significant in every case but one (K62-67), indicating genetic differences were present (Table 2). One seedling each of Nemaguard and P101-41 displayed no tree losses to PTSL through Spring 1991 (Fig. 2), indicating that apparently superior individuals can be identified in otherwise inferior families. We would caution, however, that although eight of eight ramets alive is statistically different from three of eight alive, some of the surviving plants may have been escapes. Genetic (seedling) variation was significant for most rootstocks; however, it was significantly larger than environmental variability (block) only for survival of Nemaguard and P101-41 $(P<0.01$, folded $\mathrm{F}$ test, data not shown). Both of these lines had performed poorly overall but each appeared to have an apparently superior individual. Lovell performed the best overall, with intermediate genetic variability.

Estimates of variance components (Table 3) indicate that the major sources of variation are seedling genotype and experimental error (unknown). The latter includes both within-block variation and block $\times$ seedling interaction. This interaction would be large when ramets of superior seedlings survived in blocks where most other plants had died, which appears to be the case here. However, multiple ramets of each seedling within each block would be needed to separate block $\times$ seedling interaction from within-block variation. Therefore, we cannot be certain of the relative size of each component. Heritability estimates based 

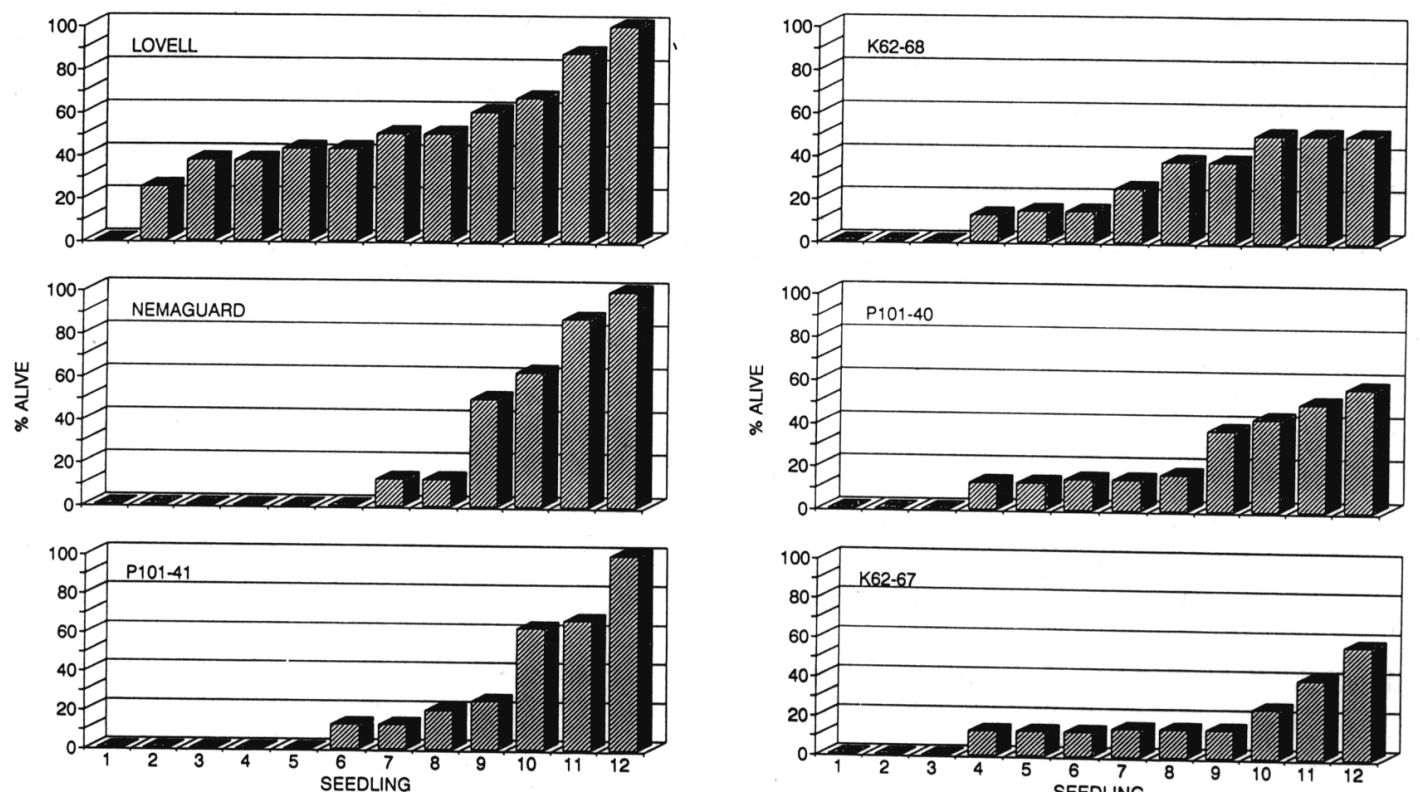

Fig. 2. Survival distribution of individual peach seedlings within rootstock families on a PTSL site after 6 years.

Table 3. Analysis of variance and estimates of variance components $\left(\sigma^{2}\right)$ and broadsense heritability $(\mathrm{H})$ for survival and longevity of peach rootstocks planted on a PTSL site.

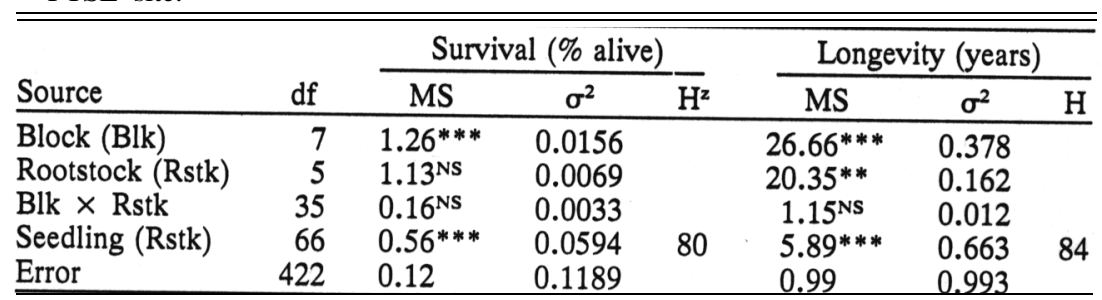

NS, $* * * * *$ Nonsignificant or significant at $P=0.01$ or 0.001 levels, respectively,

on clonally replicated seedlings as selection units are high (Table 3). These estimates are only applicable to this genetic material and this type of clonal replication.

Experiments of this type also allow the estimation of the effect of varying the number of blocks and seedlings on the theoretical variance of rootstock means, e.g., longevity (Fig. 3 ). Based on the results of this experiment, returns diminish rapidly with more than eight blocks and eight seedlings of each test rootstock family. Response is similar for survival (data not shown).

An advantage of screening clonally replicated materials is that it allows the identification of superior individuals in the initial screening, in contrast to a conventionally replicated planting using genetically different seedlings in each block. In the latter case, the best strategy available (in the absence of any correlation between growth characteristics and longevity) is to select randomly from the survivors in those blocks exhibiting the greatest mortality. These individuals must then be cloned and re-tested to verify their superiority, which requires an additional 5 to 8 years. The obvious trade-offs of additional labor input to produce and track clones and increased land use will limit the application of clonal replication to only the most promising materials for which prescreening (for other desirable traits) has been done or for which the production of a large seedling population is difficult (for instance, species hybrids).

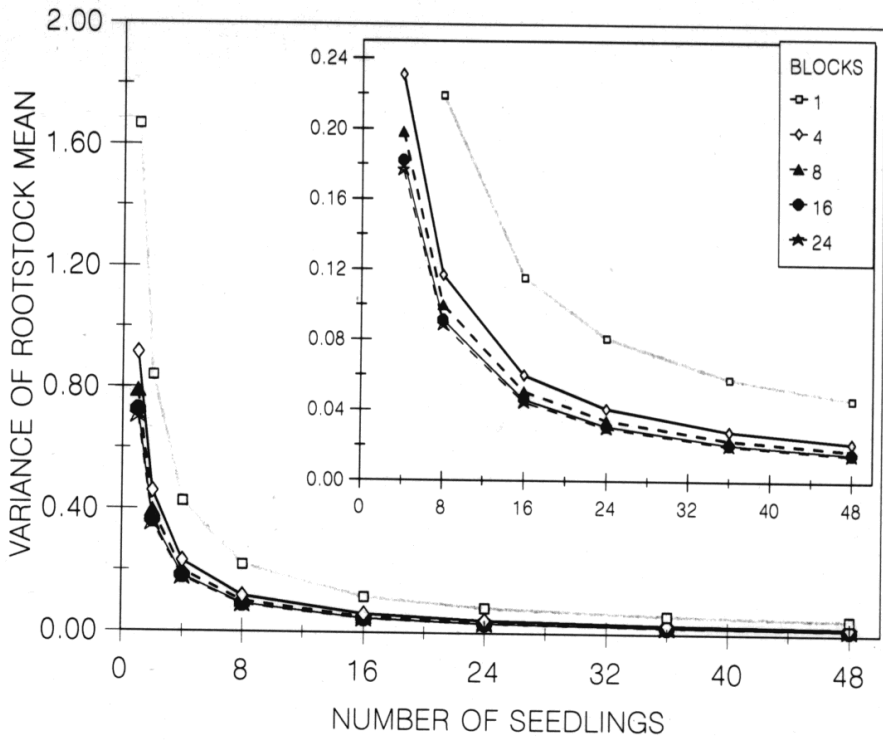

Fig. 3. Effect of varying numbers of blocks (ramets) and seedlings on the theoretical variance of rootstock mean for longevity (mean tree life). Inset shows expanded view of low variance region. Variance of rootstock mean $=\left(\sigma_{\mathrm{B} \times \mathrm{R}}^{2} / \mathrm{b}\right)+\left(\sigma_{\mathrm{S}(\mathrm{R})}^{2} / \mathrm{s}\right)+\left[\sigma_{\mathrm{e}}^{2} /(\mathrm{b} \times\right.$ s)]. 
A comparison of survival for cuttings and seedlings of longlived vs. short-lived seedlings is still needed. A superior seedling possibly could survive well as a clone but not produce longlived seedlings. Because clonal experiments are rarely performed using seed propagated crops, the amount of genetic variability within apparently uniform standards as Lovell and Nemaguard is unknown. Our results suggest that useful variation may, in fact, be present in both.

\section{Literature Cited}

Brittain, J.A. and R.W. Miller, Jr. (eds.). 1978. Managing peach tree short life in the Southeast. Clemson Univ. Coop. Agr. Ext. Ser. Circ. 585.

Byrd, D.W., Jr., K.R. Barker, H. Ferris, C.J. Nusbaum, W.E. Griffin, R.H. Small, and C.A. Stone. 1976. Two semi-automatic elutriators for extracting nematodes and certain fungi from soil. J. Nematol. 8:206-212.

Dudley, J.W. and R.H. Moll. 1969. Interpretation and use of estimates of heritability and genetic variances in plant breeding. Crop Sci. 9:257-262.

Dozier, W.A., Jr., J.W. Knowles, C.C. Carlton, R.C. Rom, E.H.
Arrington, E.J. Wehunt, U.L. Yadava, S.L. Doud, D.F. Ritchie, C.N. Clayton, E.I. Zehr, C.E. Gambrell, J.A. Britton (sic), and D.W. Lockwood. 1984. Survival, growth and yield of peach trees as affected by rootstocks. HortScience 19:26-30.

Jenkins, W.R. 1964. A rapid centrifugal-flotation technique for separating nematodes from soil. Plant Dis. Rpt. 48:692.

Jones, G.L., D.F. Matzinger, and W.K. Collins. 1960. A comparison of flue-cured tobacco varieties repeated over locations and years with implications on optimum plot allocation. Agron. J. 52:195-199.

Nyczepir, A.P. 1990. Influence of Criconemella xenoplax and pruning time on short life of peach trees. J. Nematol. 22:97-100.

Nyczepir, A.P., E.I. Zehr, S.A. Lewis, and D.C. Harshman. 1983. Short life of peach trees induced by Criconemella xenoplax Plant Dis. 67:507-508.

Okie, W.R. 1984. Rapid multiplication of peach seedlings by herbaceous stem cuttings. HortScience 19:249-251.

Ritchie, D.F. and C.N. Clayton. 1981. Peach tree short life: A complex of interacting factors. Plant Dis. 65:462-469.

SAS Institute. 1987. SAS/STAT guide for personal computers. version 6 (ed.). Cary, N.C.

Sharpe, R.R., C.C. Reilly, A.P. Nyczepir, and W.R. Okie. 1989. Establishment of peach in a replant site as affected by soil fumigation, rootstock, and pruning date. Plant Dis. 73:412-415. 